\title{
ISCoS spinal cord injury worldwide awareness day-September 5
}

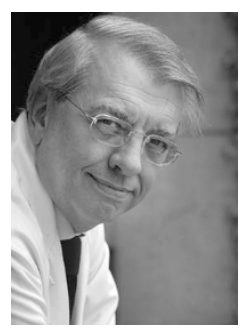

\author{
JJ Wyndaele \\ Antwerp, Belgium \\ E-mail: wyndaelejj@skynet.be
}

This September issue of Spinal Cord is one in a series of larger issues. As announced, more papers will be printed in an issue every month in order to improve publishing times. Spinal Cord Series and Cases continues to develop and has become a continuous publication, so that accepted papers will very quickly be picked up by search engines and become available to all. This has replaced the quarterly online issue publication.

September 2016 will be an important month for SCI individuals and SCI management. September 5 will be worldwide SCI awareness day. It is important that attention is drawn to SCI everywhere. Many scientific societies and patients' groups work together to get the data on SCI into the public sphere. Prevention, care, outcome, and development will be of interest for health authorities and most people in the general population. The intention is to repeat this event every year with an increasing number of activities. September has been chosen as the most suitable month.

September is also the month when ISCoS will hold his Annual Scientific Meeting in Vienna from 14-19. It will be an important meeting and I hope many of you can participate in the presentations, poster sessions, workshops and informal gatherings and talks.

This SC issue contains papers on very different topics, all interesting and of high scientific value.

The decision has been made to transfer the Editorial Office to central ISCoS administration in Stoke Mandeville. You will be hearing about this in the following months.

Enjoy reading and see you in Vienna.

Spinal Cord (2016) 54, 627; doi:10.1038/sc.2016.127 